\title{
CORRESPONDENCE
}

\section{Uvular trauma caused by endotracheal tube}

\section{Saurabh Bhargava, Zara Wani, Meenaxi Sharma}

Uvula is a small tongue-shaped piece of tissue hanging from the posterior aspect of the soft palate. It is made up of soft connective tissue covered by an epithelium and is highly vascular. ${ }^{[1]}$ It prevents micro-organisms from entering into the digestive tract. It is prone to inflammation and the condition is known as uvulitis, which presents as breathing problems, choking sensations, discomfort in the throat and in the surrounding areas, difficulty in deglutition, snoring, fever and change in voice. General anaesthesia is a very rare cause of injury to uvula and we present such a case. ${ }^{[2]}$

A 25-year-old male, a diagnosed case of right temporal glioma, underwent right temporal craniotomy and tumour excision at our institute. He had no significant past medical history, was a non-smoker and there was no history of recent upper respiratory tract infection. His airway was graded to be Mallampati Class I during pre-anaesthetic check-up. In the operation theatre, tracheal intubation was done using a size \#4 Macintosh laryngoscope blade and an $8.5 \mathrm{~mm}$ (ID) cuffed endotracheal tube. Intubation was smooth and achieved in the first attempt. The intra-operative period was uneventful. In the post-operative period, he was electively ventilated till the next morning, in the Intensive Care Unit (ICU). The patient was extubated after ascertaining the criteria for extubation, following which he complained of throat discomfort. He was given steam inhalation, and he further complained of foreign body sensation in the throat along with difficulty in swallowing. Examination of the throat using a laryngoscope revealed a congested, swollen and elongated uvula with a necrosed tip [Figure 1]. The patient was reviewed by a laryngologist, who considered the possibility of a uvulitis due to trauma induced by endotracheal tube. The patient was advised for intravenous injections of antibiotics such as ceftriaxone

Department of Anaesthesiology and Critical Care, NIMS Medical College and Hospital, Jaipur, Rajasthan, India

Address for correspondence:

Dr. Zara Wani, NIMS Medical College and Hospital,

Jaipur, Rajasthan, India.

E-mail: zarawani14@yahoo.com

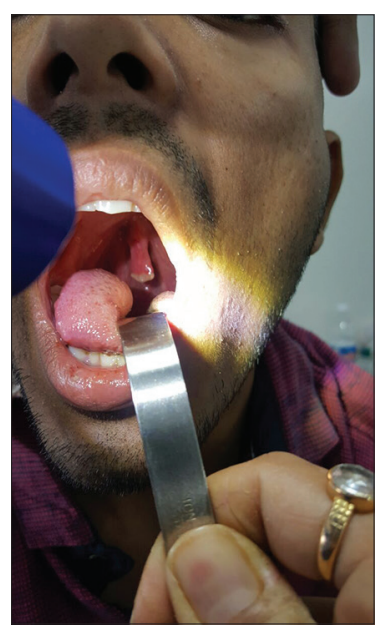

Figure 1: On examination, a congested, swollen and elongated uvula found with necrosed tip

and amikacin along with saline gargles, steam inhalation and gargles of viscous lignocaine intermittently. The patient continued this treatment and the symptoms slowly abated with more than $50 \%$ recovery on day 4 [Figure 2]. By the time he was discharged on day 7, his symptoms had almost completely resolved. Examination of the throat revealed normal-sized uvula with minimal congestion and no ulceration.

Traumatic uvulitis has been reported in adults after general anaesthesia due to endotracheal intubation ${ }^{[3]}$ or laryngeal mask airway, ${ }^{[4]}$ as well as after endoscopy. ${ }^{[5]}$ The injury to uvula is likely due to compression of the uvula against the surrounding structures, leading to ischaemia, inflammation and necrosis. ${ }^{[3]}$ The incidence of post-operative sore throat after tracheal intubation varies from $14 \%$ to $50 \%$, so also hoarseness. Contributing factors include the size of the tube, cuff design and pressure, variation in skills and techniques between anaesthesiologist and the subjectivity of the symptom of sore throat in individual patients. ${ }^{[6]}$ It may also occur after aggressive oro-pharyngeal suctioning. ${ }^{[7]}$ The prevention of secondary infection should be considered in such cases; hence, a wide-spectrum antibiotic prophylaxis is indicated. Analgesia and anti-inflammatory therapy is necessary as the pain is severe. Specific treatment such as antibiotics and antiviral drugs are controversial but important to prevent secondary infection. Uvular ulceration and necrosis may also occur due to prolonged procedural time such as in neurosurgery. The patient's haemodynamic status as well as unusual anatomy of the oral cavity may also contribute. An ulcerated uvula may necrose or become infected and may represent a source of unexplained infection post-procedure. ${ }^{[4]}$ Apart from conservative management, proper counselling 


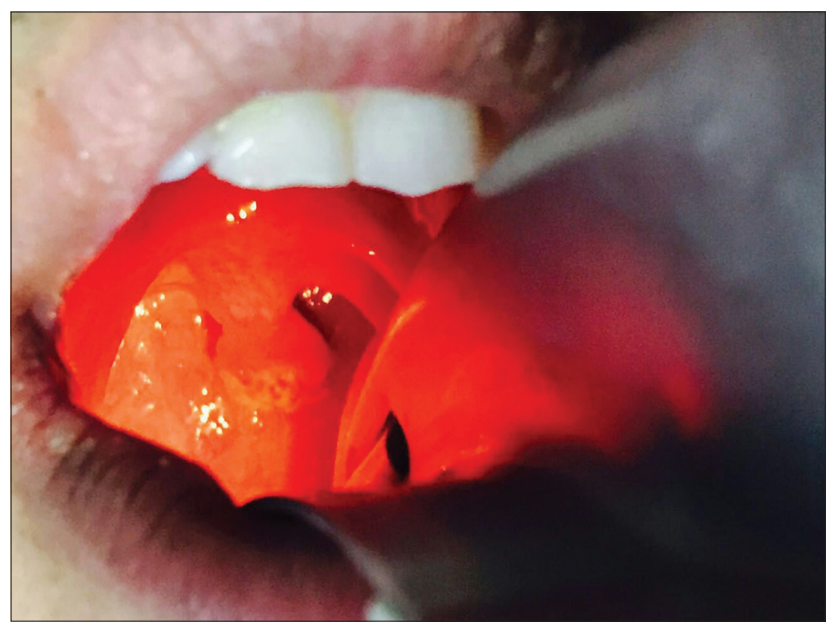

Figure 2: Day 4 with more than $50 \%$ recovery after the patient was put on conservative management

of the patient is of great importance as uvulitis can be extremely distressing.

We would like to conclude by drawing emphasis on the two factors that are pertinent to this condition, namely, the size of the endotracheal tube and the purpose of its placement. The need for endotracheal intubation beyond the operation room should also have a bearing in our minds, especially in the setting of the ICU. ${ }^{[6]}$

\section{Declaration of patient consent}

The authors certify that they have obtained all appropriate patient consent forms. In the form the patient has given his consent for his images and other clinical information to be reported in the journal. The patients understand that their names and initials will not be published and due efforts will be made to conceal their identity, but anonymity cannot be guaranteed.

\section{Financial support and sponsorship Nil.}

\section{Conflicts of interest}

There are no conflicts of interest.

\section{REFERENCES}

1. Martin LD, Mhyre JM, Shanks AM, Tremper KK, Kheterpal S. 3,423 emergency tracheal intubations at a university hospital: Airway outcomes and complications. Anesthesiology 2011;114:42-8.

2. Harris MA, Kumar M. A rare complication of endotracheal intubation. Lancet 1997;350:1820-1.

3. Emmett SR, Lloyd SD, Johnston MN. Uvular trauma from a laryngeal mask. Br J Anaesth 2012;109:468-9.

4. Peghini PL, Salcedo JA, Al-Kawas FH. Traumatic uvulitis: A rare complication of upper GI endoscopy. Gastrointest Endosc 2001;53:818-20.

5. Farrow S, Farrow C, Soni N. Size matters: Choosing the right tracheal tube. Anaesthesia 2012;67:815-9.

6. Gilmore T, Mirin M. Traumatic uvulitis from a suction catheter. J Emerg Med 2012;43:e479-80.

7. Christodoulou C, Friesen J. The Bullard laryngoscope and uvular edema. Can J Anaesth 2004;51:401-2.

This is an open access article distributed under the terms of the Creative Commons Attribution-NonCommercial-ShareAlike 3.0 License, which allows others to remix, tweak, and build upon the work non-commercially, as long as the author is credited and the new creations are licensed under the identical terms.

\begin{tabular}{|l|l|}
\hline \multicolumn{2}{|c|}{ Access this article online } \\
\hline Quick Response Code: & Website: \\
\hline & www.jnaccjournal.org \\
\cline { 2 - 2 } & \\
\hline
\end{tabular}

How to cite this article: Bhargava S, Wani Z, Sharma M. Uvular trauma caused by endotracheal tube. J Neuroanaesthesiol Crit Care $2017 ; 4: 183-4$. 